\title{
Improving Productivity Based on Evaluation Score of Overall Equipment Effectiveness (OEE) Using DMAIC Approach on Blistering Machine
}

\author{
Mohamad Sukma Hervian', Chandrasa Soekardi \\ ${ }^{1,2}$ Master's Program in Industrial Engineering, Mercu Buana University, Jakarta, Indonesia
}

\begin{abstract}
In a turbulent and competitive business environment at present, many organizations are forced to execute various productivity improvement programs in order to survive. One of the many approaches to do this is by developing and implementing Total Productive Maintenance (TPM). The TPM is a world-class leading manufacturing strategy to manufacture close to ideal condition with zero downtime, zero defects, and competitive cost leadership to achieve competitive advantage. The most common metric used by managements to measure the main effectiveness and success of the TPM is the Overall Equipment Effectiveness $(\mathrm{OEE})$. It is the main performance indicator focusing on the availability of equipment, performance efficiency and level of quality. This study discusses the use of the DMAIC approach to systematically apply Define, Measure, Analyze, Improve and Control on the performance of the equipment. The aims of this study are to discuss and to focus on the application of the DMAIC approach to reduce the existing bottleneck process, highlighting mainly on the current performance of the OEE.
\end{abstract}

Keywords: TPM, OEE, Six Big Losses, DMAIC

\section{Introduction}

At the moment the industry holds a crucial role in the development era in Indonesia. The emergence of small and large industries, both private and state-owned enterprises, will become the puncheons in developing the country. In the industry, the quality of the product and productivity are success key factors in various production systems. Both factors are critical performance criteria in a profit-oriented company. Economy-wise, the globalization era is marked by the emergence of free-trade agreements, particularly in Asian-Pacific countries (AFTA) in 2003. A free-trade system means that all goods and services produced by a country can be freely distributed to the said regions without restrictions from each country. This free-trade era, if reviewed from the customers' perspective, would be highly beneficial, since consumers would have a variety of options in fulfilling their needs. If reviewed from the producers' perspective especially in Indonesia, this kind of trade could be a threat, particularly against the rush of products coming from abroad.

When the tariff regulations were no longer in effect due to the free-trade agreement, there would be tight competition among producers. An operations division in a company often faces the issue of how to manufacture a product of good quality and competitive price. Therefore, costs resulting from losses such as time inefficiency, reduced speed of machine, and other factors hampering the production process must be minimized and eliminated. To minimize those problems, the company needs to be supported by adequate equipment and labor.

Based on research conducted by Vijayakumar and Puvanasvaran, it shows that through evaluation of OEE values and comparing it with OEE values in the Standard World Class Manufacturing and also eliminating Six Big Losses it has been an effective way to improve engine performance $[1,2]$.

\section{Literature Review}

Productivity is a measure that expresses how well the resources are organized and utilized to achieve optimum results [3]. Productivity can be used as a measure of the success of an industry in producing goods or services.

OEE is a performance measurement tool of the whole equipment (complete, inclusive, whole) meaning that the equipment can function as it is intended to. The OEE is also a three-part tool to analyze the performance of equipment based on availability, production effectiveness, and quality of the product or output.

The OEE score is derived from the multiplication of three elements: availability, production effectiveness, and quality rate. The mathematical formula is as follows [4]:

$$
\begin{gathered}
\mathrm{OEE}=\text { Availability } x \text { Performance efficiency } x \\
\text { Rate of quality product } \mathrm{x} 100 \%
\end{gathered}
$$

The result of the formula takes the form of a percentage figure representing the level of effectiveness of the usage of equipment. In its application, the figures vary depending on the equipment. Nonetheless, to become a profitable business, it is advised to have an OEE score of at least $85 \%$ with the composition of availability of over $90 \%$, production effectiveness of over $95 \%$, and quality of production of over $99 \%$.

Nakajima asserts that there are three elements in the OEE:

\section{Availability}

This is the ratio of the operation time to the loading time. To calculate the machine availability the values of the following aspects are required: operation time, loading time, and downtime. 


\section{International Journal of Science and Research (IJSR) \\ ISSN (Online): 2319-7064}

Index Copernicus Value (2013): 6.14 | Impact Factor (2015): 6.391

Availability is calculated using the following formula:

$$
\begin{aligned}
& \text { Availability }=\frac{\text { operation time }}{\text { loading time }} \times 100 \\
& \text { Availability }=\frac{\text { loading time }- \text { down time }}{\text { loading time }} \times 100 \%
\end{aligned}
$$

Loading time is the availability of time per day or per month subtracted by the planned downtime.

$$
\begin{aligned}
& \text { Loading time }=\text { Total availability }- \text { Planned } \\
& \text { downtime }
\end{aligned}
$$

Planned downtime is the total machine downtime for scheduled maintenance or other managerial activities. Operation time is the result of subtracting loading time with machine downtime (non-operation time). In other words, operation time is the availability time of operation after machine downtime is subtracted by planned total availability time. The machine downtime is the time process that is supposed to be used by the machine, but due to equipment failure no output is produced. The downtime includes the machine breaking down due to damage of the equipment, replacement of dies, the implementation of setup procedures and adjustments, and others.

\section{Performance Efficiency Rate}

Performance efficiency is the product of the operation speed rate and net operation rate, or the ratio of the quantity of products manufactured multiplied by the ideal cycle time to the available time for the production process (operation time). Operation speed rate is the ratio between the ideal machine speed based on actual machine capacity (theoretical/ideal cycle time) with the actual machine speed (actual cycle time). The arithmetic equation is shown as follows:

$$
\begin{aligned}
& \text { Operation Speed Rate }=\frac{\text { ideal cycle time }}{\text { actual cycle time }} \\
& \text { Net Opertion Rate }=\frac{\text { actual processing time }}{\text { operation time }}
\end{aligned}
$$

Net operation rate is the ratio between the number of products processed (processed amount) multiplied by the actual cycle time with the operation time. The net operation time is useful to calculate the loss caused by minor stoppages and the reduced speed of production (reduced speed). There are three important factors required to calculate performance efficiency: ideal cycle, processed amount, and operation time.

The performance efficiency can be calculated as follows:

$$
\begin{aligned}
& \text { Performance Efficiency }=\text { Net Operating } x \\
& \text { Operating Speed Rate }
\end{aligned}
$$

$$
\frac{\text { processed amount } x \text { ideal cycle time }}{\text { operating time }} \times 100 \%
$$

\section{Quality of Product Rate}

Nakajima asserts that the rate of product quality is the ratio of the number of better products to the number of processed products. Therefore, the rate of quality product is the calculation using two factors, which are the processed amount (the number of products processed) and the defect amount (the number of defect products).

The rate of product quality is calculated as follows:

$$
\frac{\text { processed amount - defect amount }}{\text { processed amount }} \times 100 \%
$$

OEE is the best measurement tool available to optimize the manufacturing process and is directly related to operational costs. It is a reporting tool on the losses and obstacles during a process, and a network of financial decision making and factory operations performance to justify every new decision on investing.

TPM is a lifecycle approach that is integrated with plant maintenance [5]. TPM can be used effectively by organizations to develop worker involvement in every step of the manufacturing process and maintenance facility to further streamline the production flow, improve product quality, and reduce operating costs.

The TPM provides a pathway to achieve perfection in terms of planning, organizing, monitoring and arranging through 8 (eight) pillars of TPM, which include (1) Autonomous Maintenance, (2) Focused Improvement, (3) Planned Maintenance, (4) Quality Maintenance, (5) Education and Training, (6) Safety, Health, and Environment, (7) Office TPM, and (8) Development Management [6].

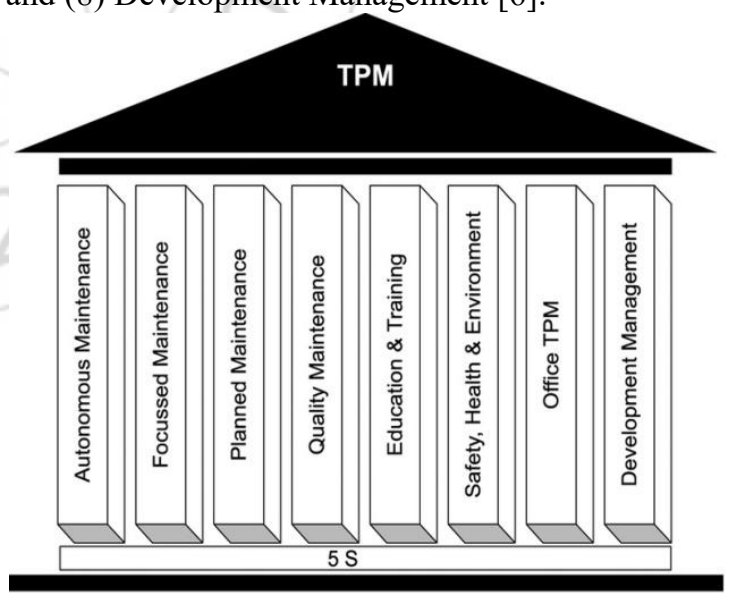

Figure 1: The Pillars of TPM

The benefits reaped from TPM implementation can be direct or indirect, which are achievement of the minimum Overall Plant Efficiency (OPE) of $80 \%$, achievement of the minimum OEE of $90 \%$, improved quality to minimize customer complaints, reduced manufacturing costs by $30 \%$, fulfilled consumer orders by $100 \%$, reduced work accidents, and compliance to pollution measurement control. 


\section{International Journal of Science and Research (IJSR) \\ ISSN (Online): 2319-7064}

Index Copernicus Value (2013): 6.14 $\mid$ Impact Factor (2015): 6.391

\section{Analysis Method}

Quantitative data analysis using DMAIC was employed in this analysis. The Minitab software was used to interpret and analyze the data. The two sample T-test was used in the analysis process. The two samples were of the same subject but were treated or measured differently, for example, subject A would be treated by Treatment I then by Treatment II.

\section{Data and Analysis}

The Pareto chart method was used to find out which factors contributed a percentage of $80 \%$. Based on downtime causes data, line clearance caused 10,055 hours of downtime with a percentage of $30.71 \%$. Setting caused 6,665 hours of downtime with a percentage of $20.36 \%$. Minor stoppages caused 4,814 hours of downtime with a percentage of $14.70 \%$. Preparation caused 3,069 hours of downtime with a percentage of $9.37 \%$. Equipment failure caused 2,440 hours of downtime with a percentage of $7.45 \%$. Trial caused 2,057 hours of downtime with a percentage of $6.28 \%$. Material replacement caused 1,531 hours of downtime with a percentage of $4.68 \%$. Missing tablet caused 1,153 hours of downtime with a percentage of $3.52 \%$. Rework caused 572 hours of downtime with a percentage of $1.75 \%$. Utility failure caused 254 hours of downtime with a percentage of $0.78 \%$. Lastly, shift handover caused 130 hours of downtime with a percentage of $0.40 \%$

If we plot the existing data into the Pareto chart, the following data are obtained:

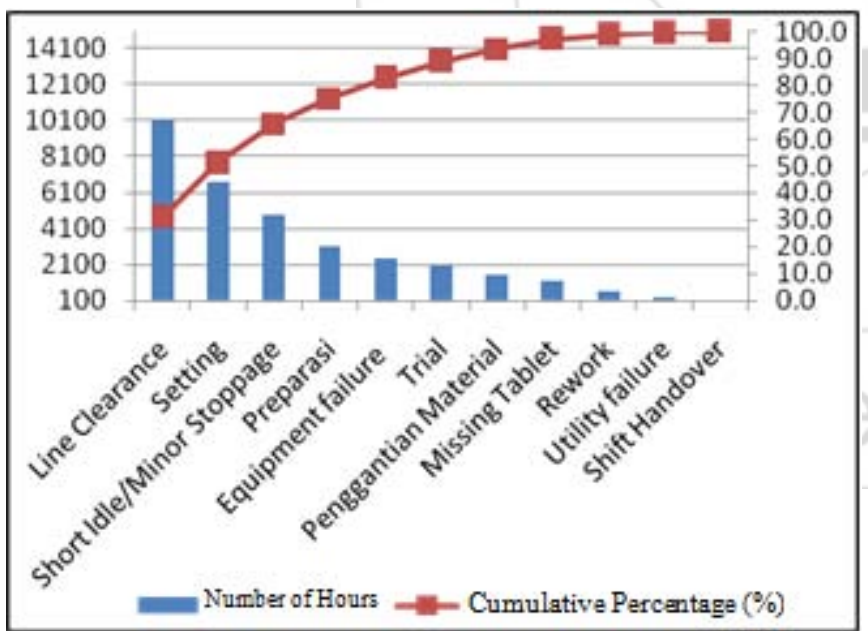

Figure 2: Pareto Chart of Performance and Availability

After the causes of the greatest contributions had been revealed, an analysis using the Cause-Effect Diagram was carried out

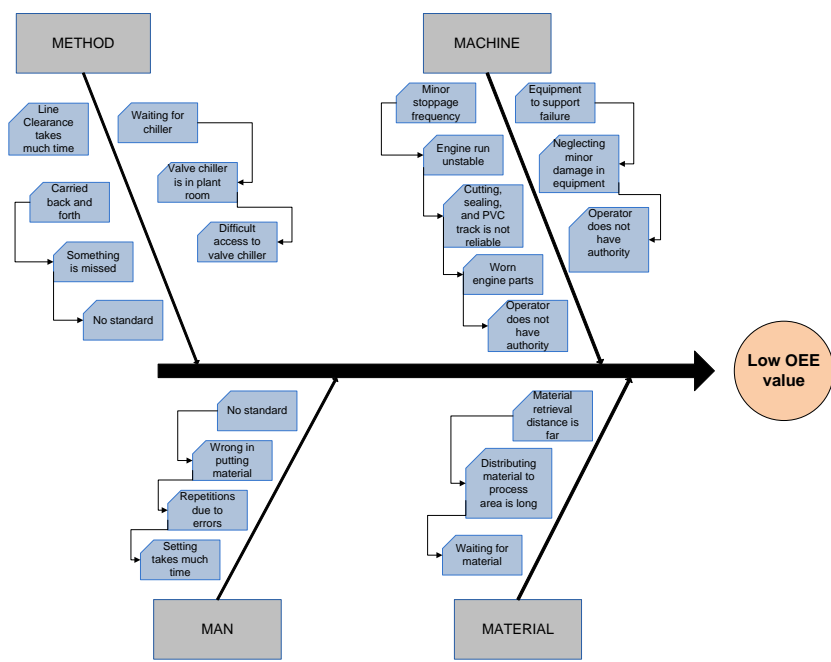

Figure 1: Fishbone Diagram of the Causes of the Low OEE

To improve the OEE score, the main cause of each downtime needed to be corrected, with the corrective actions as follows:

1. Labor standards and checklist made the line clearance workflow easier and eliminate back and forth workflow and also ensure that all the work done followed the standards and that nothing was overlooked [7].

2. Poka-Yoke was employed to eliminate errors when setting and implementing $5 \mathrm{~S}$ to maintain the work area in order and to facilitate tool searching by using labeling and placement design tools to avoid occurrence of blunders when picking up the tools [8].

3. Autonomous maintenance was implemented so that operators could independently maintain engine performance, minimize repair time and were expected to be able to determine the necessity of spare parts replacement or be able to detect damage before repair that required a long time [9].

4. Chilled water access was moved from the plant room to an area near the machine to facilitate the chilled water valve settings.

5. The buffer stock on WIP near blistering process was made for the next batch of materials. This improvement was intended to avoid waiting time in the process regarding materials.

After corrective actions had been implemented, a statistical analysis on the OEE score before and after the improvement was conducted on the blistering machine, Duan Kwei. The data were taken 30 times for each OEE score on the measurement before and after the improvement.

Before the analysis was conducted, the data obtained had to be calculated using a normality test. The normality test was used as a validity test on the data to be tested using a 2 sample t-test.

Before and after improvement the data indicate a $p$ score $>$ 0.05 , and therefore it is clear that both follow a normal distribution.

Based on the obtained data, a statistical analysis was used to compare the average of the OEE scores before and after 


\section{International Journal of Science and Research (IJSR) \\ ISSN (Online): 2319-7064}

Index Copernicus Value (2013): 6.14 | Impact Factor (2015): 6.391

measurement, using the 2 sample t-test, given the following hypotheses:

- $\mathrm{H}_{0}=$ The improvement does not have an impact on the OEE score

- $\mathrm{H}_{1}=$ The improvement has an impact on the OEE score

By using The Minitab 16 software, the data was calculated using the 2 sample t-test analysis. Based on the results, it is clear that the $p$ score $<0.05$, which indicates that the average score of OEE of the two data, before and after improvement, were significantly different.

After improvement had been carried out on the blister machine Duan Kwei, the daily OEE scores were monitored 15 times consecutively, and in the following control graph are the results of the monitoring:

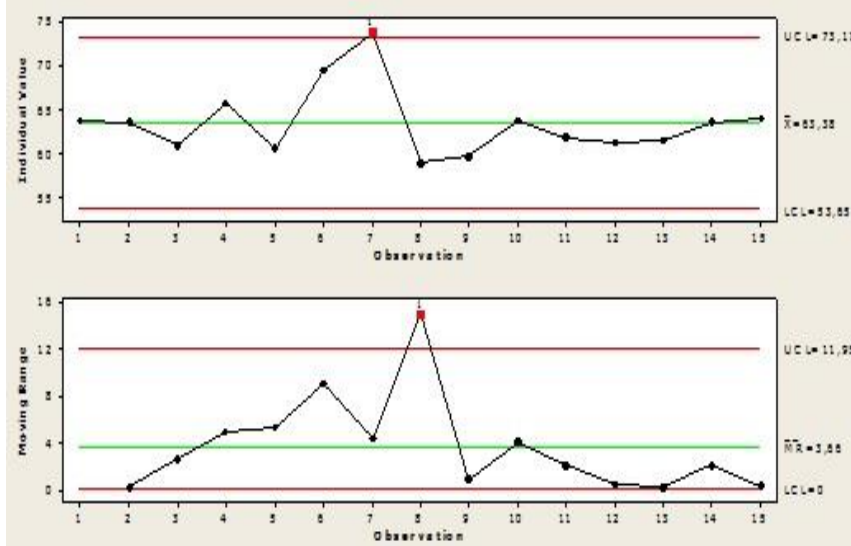

Figure 2: Control Graph on OEE Score After Improvement

Based on the control data above, after improvements had been carried out it is clear that the OEE scores varied. This is due to the lack of consistency in the implementation of corrective actions (improvement).

\section{Conclusion}

Based on previous research, TPM was used as a method to improve machine productivity. The TPM combined with the DMAIC method was initially used as a tool to improve quality in this study, but eventually it was used to find out and analyze problems and thus take corrective actions on the blister machine, Duan Kwei. In making the improvements, SMED was also used to accelerate the line clearance process. The results of the improvements indicate that the OEE score rose from $49.05 \%$ to $64.05 \%$. This indicates effective improvement, and if it is carried out consistently, it will yield favorable results.

\section{References}

[1] Vijayakumar, S. R., \& Gajendran, S. (2014). Improvement of overall equipment effectiveness (OEE) in injection moulding process industry. IOSR Journal of Mechanical and Civil Engineering (IOSR-JMCE), 27, 47-60.

[2] Puvanasvaran, A. P., Mei, C. Z., \& Alagendran, V. A. (2013). Overall equipment efficiency improvement using time study in an aerospace industry.Procedia Engineering, 68, 271-277.

[3] Almigo, N. (2004). Hubungan antara kepuasan kerja dengan produktivitas kerja karyawan. Jurnal Psyche, 1(1).

[4] Nakajima, S. (1988). Introduction to TPM: total productive maintenance. Productivity Press, Inc, P. O. Box 3007, Cambridge, Massachusetts 02140, USA, 1988. 129.

[5] Benjamin, S. (2003). Blanchard. Logistics Engineering and Management.

[6] Venkatesh, J. (2007). An Introduction To Total Productive Maintenance (TPM). The Plant Maintenance Resource Center, 3-20.

[7] Friedli, T., Goetzfried, M., \& Basu, P. (2010). Analysis of the implementation of total productive maintenance, total quality management, and just-in-time in pharmaceutical manufacturing. Journal of Pharmaceutical Innovation, 5(4), 181-192.

[8] Kuiper, A., van Raalte, M., \& Does, R. J. (2014). Quality Quandaries: Improving the Overall Equipment Effectiveness at a Pharmaceutical Company. Quality Engineering, 26(4), 478-483.

[9] Ali, T. A., Allama, M. M., \& Parvez, M. S. (2010). A Total Productive Maintenance (TPM) Approach to Improve Production Efficiency and Development of Loss Structure in a Pharmaceutical Industry. Global Journal of Management and Business Research, 10(2).

[10]Boban, B. (2013). Enhancing Overall Equipment Effectiveness for a Manufacturing Firm through Total Productive Maintenance.

\section{Author Profile}

Mohamad Sukma Hervian pursued his bachelor's degree in Pharmaceutical Studies, Andalas University, Padang, qualifying in 2008. In the following year, he continued Apothecary Program at the School of Pharmaceutical Studies, Bandung Institute of Technology, graduating in 2010. Several non-formal educational programs he has participated in are VSM (Value Stream Mapping) Training in Jakarta (2014), and Green Belt Six Sigma Training in Jakarta (2015). He worked as a Warehouse Supervisor at PT. Kalbe Farma Cikarang in 2010, as a Production Supervisor at PT. Tunggal Idaman Abdi Jakarta from 2010 to 2013, as a Production Supervisor at PT. Tempo Scan Pacific Cikarang from 2013 to 2014, and has been a Production Supervisor at PT. Glaxo Wellcome Indonesia, Jakarta since 2014.

Chandrasa Soekardi pursued his bachelor's degree in Mechanical Engineering, Institut Teknologi Bandung in 1976, qualifying in 1984. In 1986, he continued his study of Energy Conversion Mechanical Engineering at Ecole Centrale de Lyon, France, graduating in 1987. He pursued his doctoral degree in Industrial Process Engineering, Institut National Polytechnique de Grenoble, France in 1990 and graduated in 1994 . He is now a Professor at Mercu Buana University. 